\title{
Numerical Simulation of Deformation Characteristics of Diaphragm Wall Supporting Structure of Deep Foundation Pits
}

\author{
Cui Jianhua ${ }^{1}$, Wu Sunwu ${ }^{2, *}$ \\ ${ }^{1}$ School of Civil Engineering, Anhui Jianzhu University, China \\ ${ }^{2}$ Key Laboratory of Building Structure and Underground Engineering of Anhui Province, China
}

Copyright $\bigcirc 2016$ by authors, all rights reserved. Authors agree that this article remains permanently open access under the terms of the Creative Commons Attribution License 4.0 International License

\begin{abstract}
It was numerically simulated in the paper of the deformation characteristics of the diaphragm wall in the deep foundation by using MIDAS/GTS numerical simulation software which combined with the engineering practice of deep foundation pit of Hefei New Traffic Building and the actual construction sequence of the project in order to study the deformation characteristics of the diaphragm wall. The deformation regularity of the embossed belly shape of the diaphragm wall is shown in the whole construction period. The maximum displacement value of the wall occurs near the excavation surface and falls within a certain range. The conclusion provides a reference for future similar projects throughout to compare the monitoring data with the rationality, and correctness of the modeling and simulation are verified.
\end{abstract}

Keywords Deep Foundation Pit, MIDAS/GTS, Numerical Simulation, Diaphragm Wall, Deformation Characteristics

\section{Introduction}

With the rapid development of cities and the spring up of high-rise buildings, a higher requirement to the exploitation scale and functions of underground space is putted out, many foundation pit engineering with huge scale and complex technology appeared in our sights, all these foundation pit engineering have characteristics as large excavation volume, great depth, strict boundary condition and so on, the normal supporting constructions can no longer meet the requirement of them. Diaphragm wall, as an earlier used mature technology, is using widely in foundation pit engineering.

Sun Changjun et al. [1] analyzed the deformation and mechanical law of diaphragm walls in Beijing metro line 14 foundation pit systematically. Qiu Jianchun et al. [2]. established the finite element numerical model with the background of practical foundation pit engineering to simulate the construction process, and draw the conclusion that the deformation of diaphragm walls increase when the digging depth increase. Xiong Xiaobo et al. [3] simulated the deformation of deep foundation pit support structures by use ANSYS. Du Xilei [4] studied and analyzed the deformation and stress of diaphragm wall by doing plane two dimension simulation of deep foundation pit excavation with finite element software ABAQUS. Ding Kesheng et al. [5]. studied the relation between lateral deformation of diaphragm walls and earth pressure of deep foundation pit, they chose the constructions which use top-down method in Tianjin area as objects. Ren Jianxi et al. [6]. simulated the deformation of retaining piles, stress variation of anchor cable, and the force variation of steel supporting shafts, their simulation is based on the practical background of Xi'an metro line2 North Street station deep foundation pit engineering. Qiao Ruilong [7] analyzed the horizontal displacement of retaining structures in Wuhan metro line 2 Xunlimen station deep foundation pit engineering. Long et al. [8] collected a large number of measured data of foundation pit engineering, then classified them according to soil conditions, and analyzed the influence of excavation depth and support system stiffness on deformation of foundation pit. Finno et al. [9] analyzed series of 150 plane and its corresponding spatial model, and analyzed the spatial dimension of excavation of the foundation pit and the influence of the stiffness of the support structure on the space effect by PSR (plane strain ratio).

The deformation of diaphragm wall and beam-floor internal bracing supporting structure are studied in this paper by numerical simulating the selected A1A2 pit with MIDAS/GTS finite element software in the condition of taking beams and floors of basements as internal bracing. 


\section{Engineering Introduction}

\subsection{Project Overview}

Hefei New Traffic Building Project is situated at the corner of East Changjiang Road and Shengli Road with a flat terrain; it is close to the line $1 \& 2$ retaining structures of Hefei mass rail transit in its northwest. Its underground structures are separated; the foundation pit is $112.45 \mathrm{~m}$ long at east-west direction, $54.9 \mathrm{~m}$ long at north-south direction. The buried depth of standard segment structure floor is $26.3 \mathrm{~m}$. The basement is mainly located at the strong weathered rock sandstone stratum. It is near the Gujing Hotel with a distance about $46 \mathrm{~m}$ in its north, Shengda International is at its east for a distance about $20 \mathrm{~m}$, and on its south are residential buildings with a distance $4 \sim 10 \mathrm{~m}$. It has abundant groundwater because the South Feihe River flowing past its south side and west side with a nearest distance about $59 \mathrm{~m}$. Retaining structures of the foundation pit adopt diaphragm wall, the general construction plan of Hefei New Traffic Building are given in figure 1.

The excavation method of foundation pit is Reverse Construction Method by use diaphragm wall and beam-floor inter bracing system as supporting structure, the depth of diaphragm wall is $35.3 \mathrm{~m}$, the embedded depth below the excavation face of foundation is $9 \mathrm{~m}$, and the detailed parameters of supporting structure are given in table 1 .

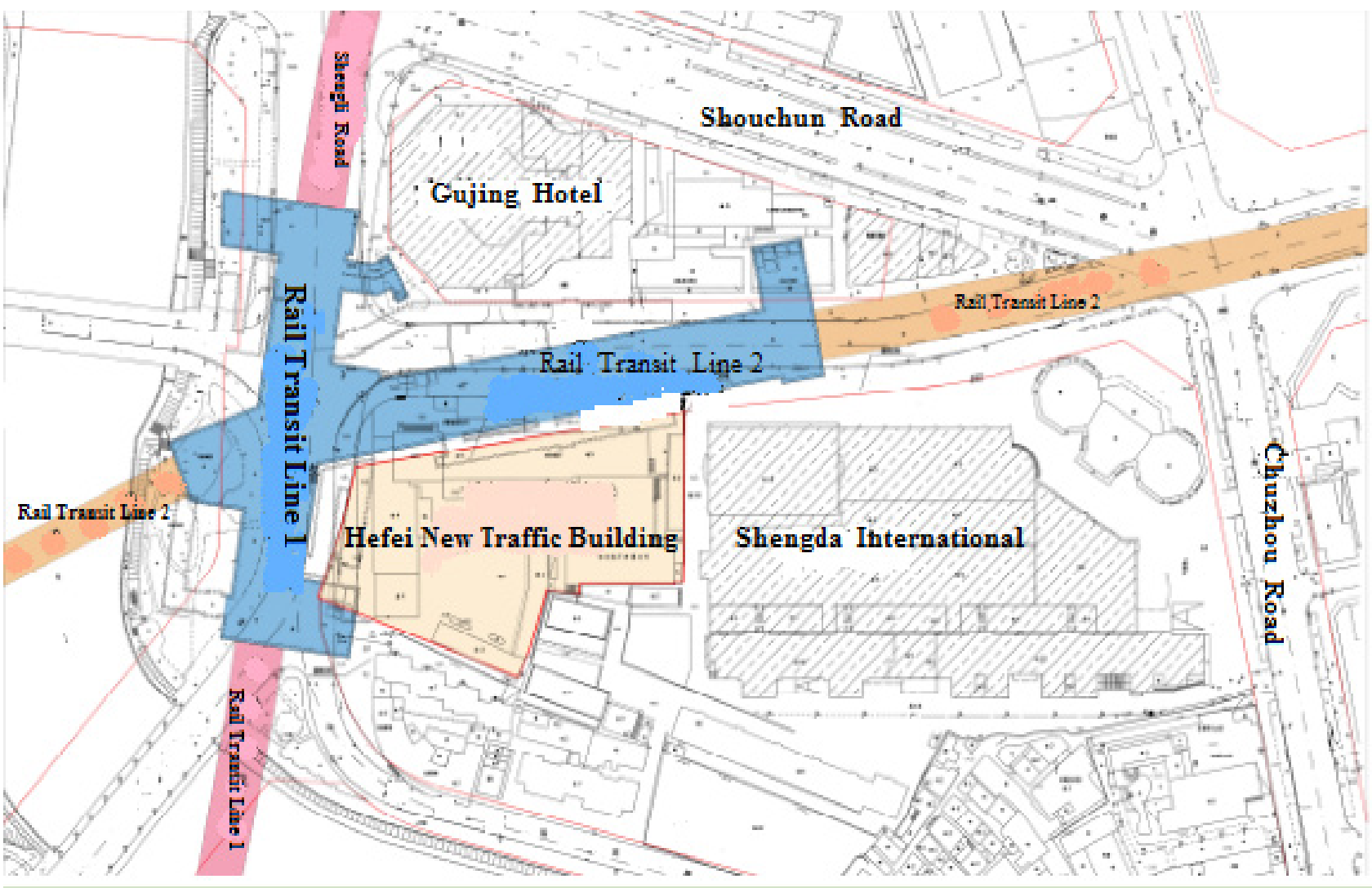

Figure 1. General Construction Plan of Hefei New Traffic Building

Table 1. Character Parameters of Retaining Structure

\begin{tabular}{|c|c|c|c|c|c|}
\hline Member & Element Type & Parameter(m) & $\begin{array}{c}\text { Bulk } \\
\text { Density }\left(\mathrm{KN} / \mathrm{m}^{3}\right)\end{array}$ & $\begin{array}{c}\text { Elastic } \\
\text { Modulus } \\
(\mathrm{MPa})\end{array}$ & $\begin{array}{c}\text { Poisson Ratio } \\
\mu\end{array}$ \\
\hline $\begin{array}{c}\text { Horizontal Support } \\
\text { Beam }\end{array}$ & $\begin{array}{l}1 \text { dimensional } \\
\text { element-beam }\end{array}$ & Section $b * h=0.6 * 0.9$ & 25 & 32500 & 0.15 \\
\hline Roof Supporting & $\begin{array}{l}2 \text { dimensional } \\
\text { element-slab }\end{array}$ & 0.4 & 25 & 32500 & 0.15 \\
\hline Standard Slab & $\begin{array}{l}2 \text { dimensional } \\
\text { element-slab }\end{array}$ & 0.35 & 25 & 32500 & 0.15 \\
\hline floor & $\begin{array}{l}2 \text { dimensional } \\
\text { element-slab }\end{array}$ & 1.2 & 25 & 32500 & 0.15 \\
\hline $\begin{array}{c}\text { Diaphragm Retaining } \\
\text { Wall }\end{array}$ & $\begin{array}{l}2 \text { dimensional } \\
\text { element-slab }\end{array}$ & 1.0 & 25 & 32500 & 0.15 \\
\hline
\end{tabular}




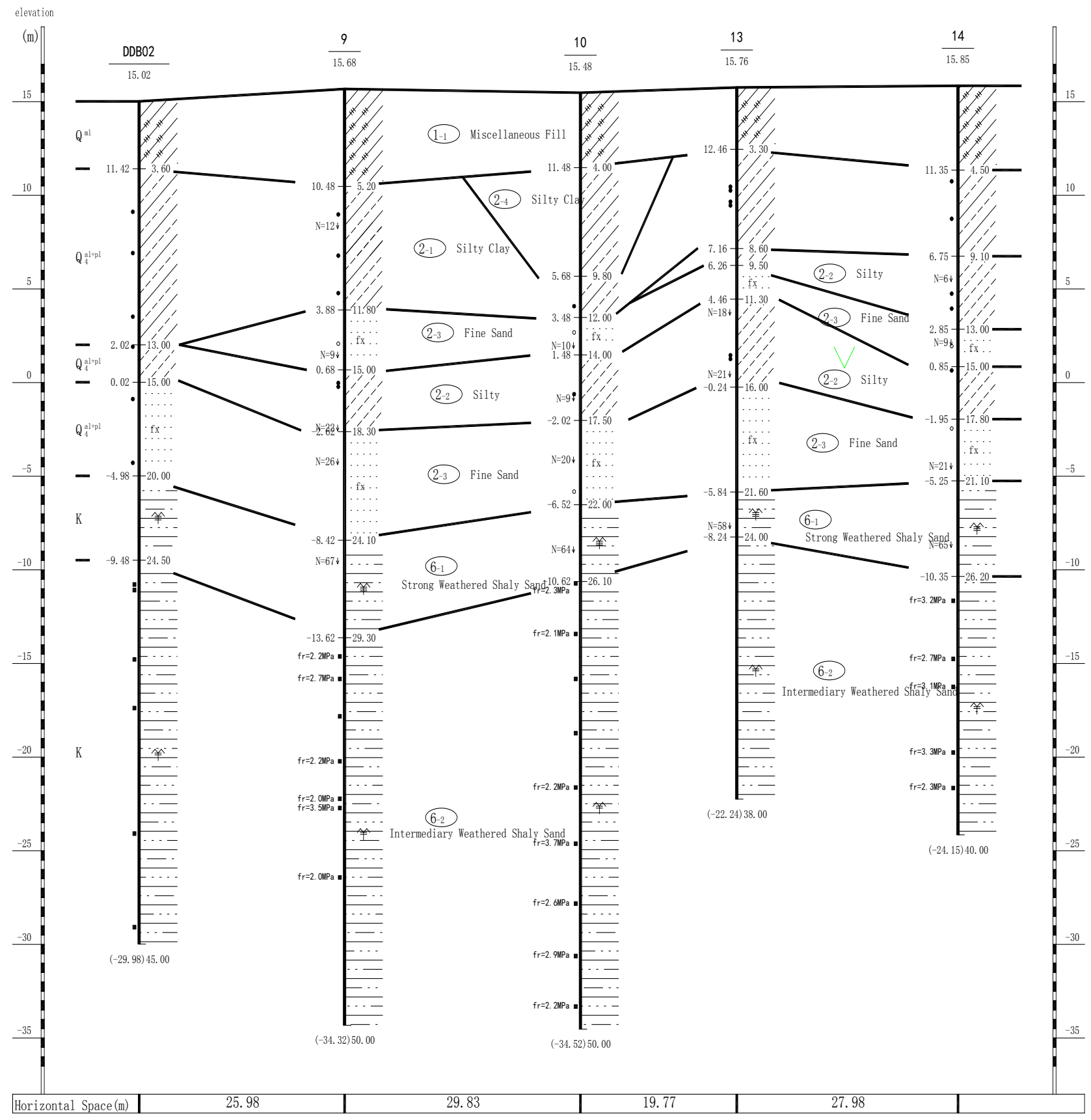

Figure 2. Engineering Geological Profile

Table 2. Physical and Mechanical Parameters of Soil Layers

\begin{tabular}{|c|c|c|c|c|c|c|c|}
\hline Soil Layer & $\begin{array}{c}\text { Thickness } \\
\text { (m) }\end{array}$ & $\begin{array}{c}\text { Bulk } \\
\text { Density } \\
\left(\mathrm{KN} / \mathrm{m}^{3}\right)\end{array}$ & $\begin{array}{c}\text { Porosity ratio } \\
\mathrm{e}\end{array}$ & $\begin{array}{l}\text { Cohesion } \\
\mathrm{C} /(\mathrm{KPa})\end{array}$ & $\begin{array}{c}\text { Internal Friction } \\
\text { Angle } /\left(^{\circ}\right)\end{array}$ & $\begin{array}{l}\text { Elastic Modulus } \\
\text { (MPa) }\end{array}$ & $\begin{array}{l}\text { Poisson } \\
\text { Ratio } \mu\end{array}$ \\
\hline Miscellaneous Fill & 4.6 & 17.5 & 0.5 & 0.5 & 8 & 10 & 0.4 \\
\hline Silty Clay & 7.5 & 19.8 & 0.679 & 38 & 14 & 33 & 0.25 \\
\hline Silty & 4.4 & 20.1 & 0.607 & 20 & 13 & 72 & 0.3 \\
\hline Fine Sand & 4.7 & 20.5 & 0.55 & 0.5 & 25 & 80 & 0.3 \\
\hline $\begin{array}{l}\text { Strong Weathered } \\
\text { Shaly Sand }\end{array}$ & 6.3 & 21 & 0.4 & 35 & 30 & 84 & 0.3 \\
\hline $\begin{array}{c}\text { Intermediary } \\
\text { Weathered Shaly } \\
\text { Sand }\end{array}$ & 22.5 & 22 & 0.35 & 40 & 40 & 100 & 0.3 \\
\hline
\end{tabular}




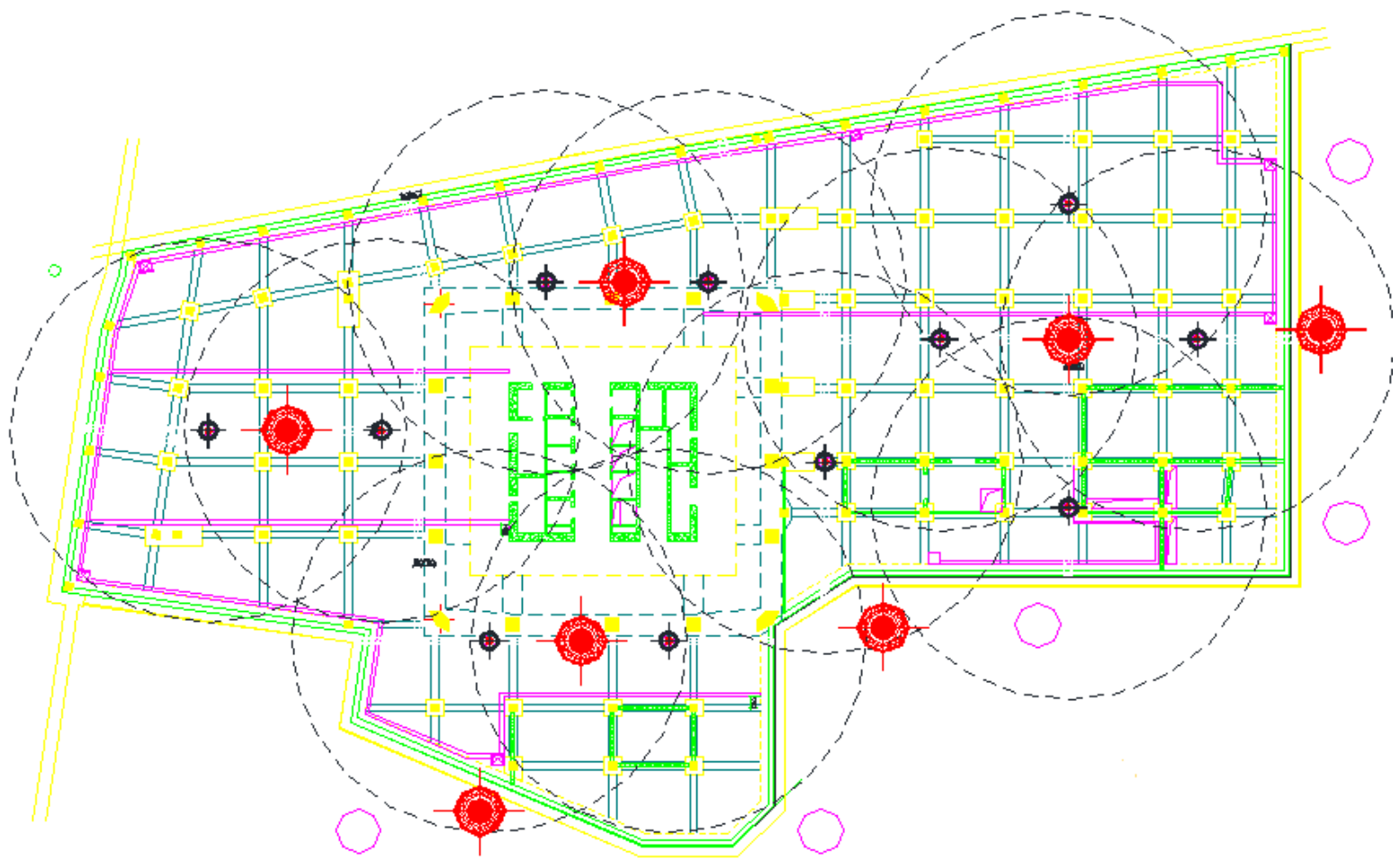

Figure 3. Plane Layout of Precipitation Wells

\subsection{Engineering Geology and Hydrogeological Conditions}

According to the geotechnical investigation report, the underground soils of the building field is artificial accumulation layer Qml, alluvium and diluvium of Holocene in Quaternary Q4al+pl, and cretaceous bedrock (K); Divided from the top to bottom as: silty clay fill layer 1 , miscellaneous fill layer 1 , silty slay 1 , silty layer 2 , fine sand 3 , silty clay 4 , strong weathered shaly sand 1 and intermediary weathered shaly sand 2 . The engineering geological profile is given in figure 2 .

According to engineering geological profile and regional engineering experience, the physical properties of different strata are given in table 2 .

Two layers of groundwater was identified in the exploration depth, they are perched water (I) and confined water (III); the perched water (I) has a stable water level of $1.35 \mathrm{~m}-2.17 \mathrm{~m}$ in buried depth and a stable water level elevation of $13.55 \mathrm{~m}-14.37 \mathrm{~m}$, the aquifer is rich in silty clay fill layer and miscellaneous fill layer1, the water amount is large. The confined water (III) has a stable water level of $1.37 \mathrm{~m}-2.19 \mathrm{~m}$ in buried depth and a stable water level elevation of $13.10 \mathrm{~m}-14.36 \mathrm{~m}$, the aquifer is rich in of silty layer 2, fine sand layer 3 and weathered rock, the water level is high. Analysis based on the regional hydrological and geological data shows that there is certain hydraulic connection between the South Feihe River and the groundwater in this area.

\subsection{Construction Precipitation}

It was combine the waterproof curtain with pit precipitation to control the groundwater; the depth of Foundation pit dewatering well hole was $27.0 \mathrm{~m}$. Meeting the demand of the excavation of the foundation pit which keeps the groundwater following the excavation. The main pit put 11 eyes of dewatering well (4 eyes inside and 3 eyes outside), the construction site of specific dewatering well throughout layout was shown in figure 3 .

\section{Data Monitoring}

Hefei New Traffic Building belongs to the deep foundation pit excavation, which with a difficult environment and Hydrogeological conditions. In order to meet the monitor and stability demand, the instrument of figure 4 and 5 was in use to monitor the displacement of retaining structures in the excavation.

Displacement sensors of horizontal displacement enclosure wall were: Around the foundation pit layout to set 23 points; displacement sensors of deep displacement enclosure wall were: Located in retaining wall closed inclined tube length should be longer than the depth of the enclosure wall reinforcing cage, and the number of monitoring stations should not be less than 1 per side, totally 17 sets. The specific arrangement of measuring points in the entire site was shown on the top of the wall , and horizontal displacement monitoring of horizontal displacement monitoring was correspond to the deep of the wall. The plane layout of measuring points is given in figure 6 . 


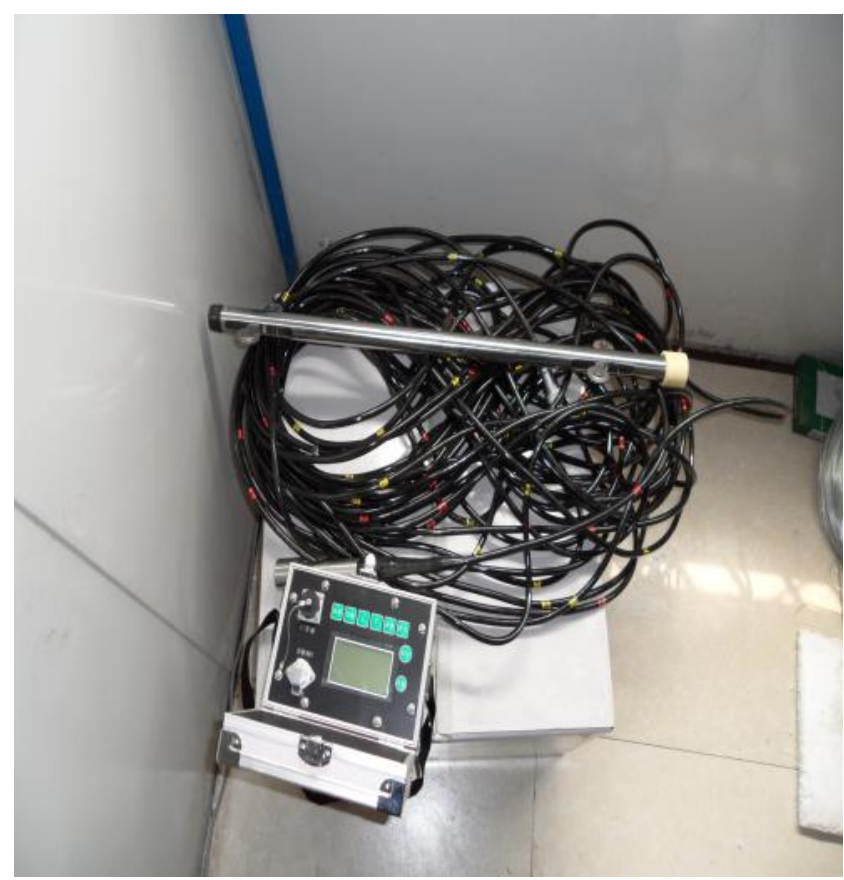

Figure 5. Nikon Nivo 1.C Series Total Station

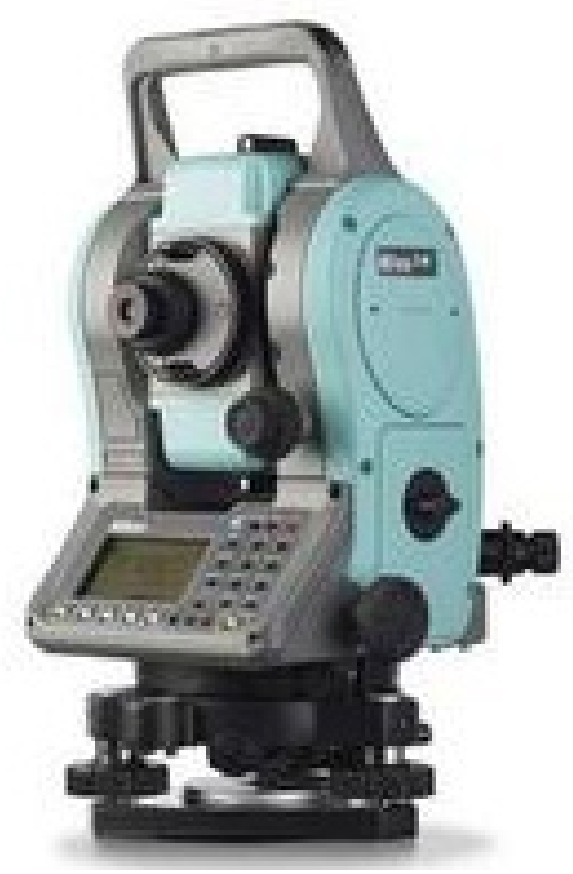

Figure 4. CX-806D Inclinometer

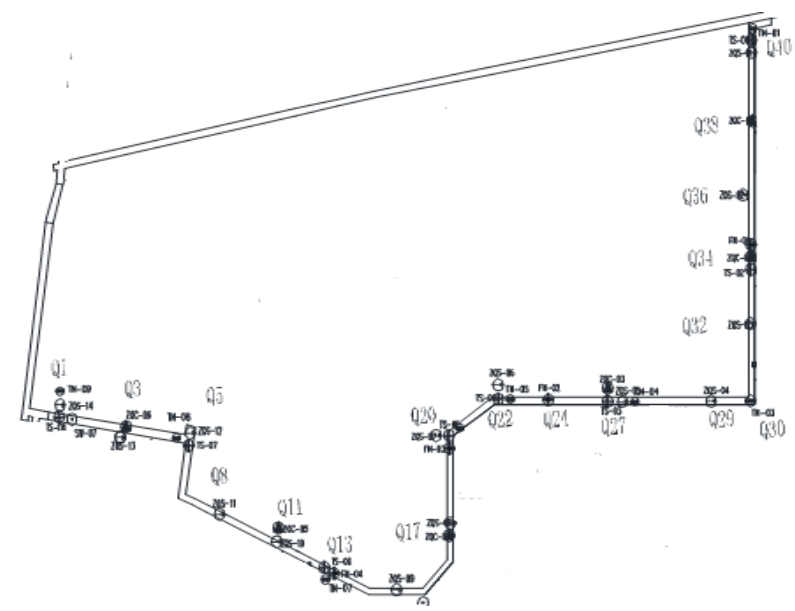

Figure 6. Plane Layout of Measuring Points

\section{Three-Dimensional Numerical Simulation}

Traditional deep pit support theory usually take care of a simply one-dimension method, which means retaining structure was simplified as the plane strain problem, and make the stepped RSRW followed the Rankine or Coulomb's soil pressure theory to calculated the soil pressure acting on retaining structure, Then according to the "equivalent beam method" or "m" method of calculation of the supporting design rationality to calculate parameters such as reinforcement of retaining structure, buried depth. However, this kind of method ignores the effect of three-dimension space, so the accuracy of the calculation results need to be strengthen. Therefore, it is necessary to establish three-dimensional model to calculate.

\subsection{Building the Model}

The modeling method is bottom-up method (point-line-surface-body). The foundation is $45 \mathrm{~m}$ long at east-west direction, $45.7 \mathrm{~m}$ long at north-south direction; the buried depth is $26.3 \mathrm{~m}$. Adjust the model size on the basis of excavation area size: the model width is $2-3$ times of the foundation pit depth, the model depth is 2-4 times of the foundation pit depth [10]. In consideration of that the model is built to analyze the deformation in excavation process, take a $100 \mathrm{~m} \times 100 \mathrm{~m} \times 70 \mathrm{~m}$ size soil as calculating region. The model is given in figure 7 . The internal bracing supporting structure is given in figure 8 . 


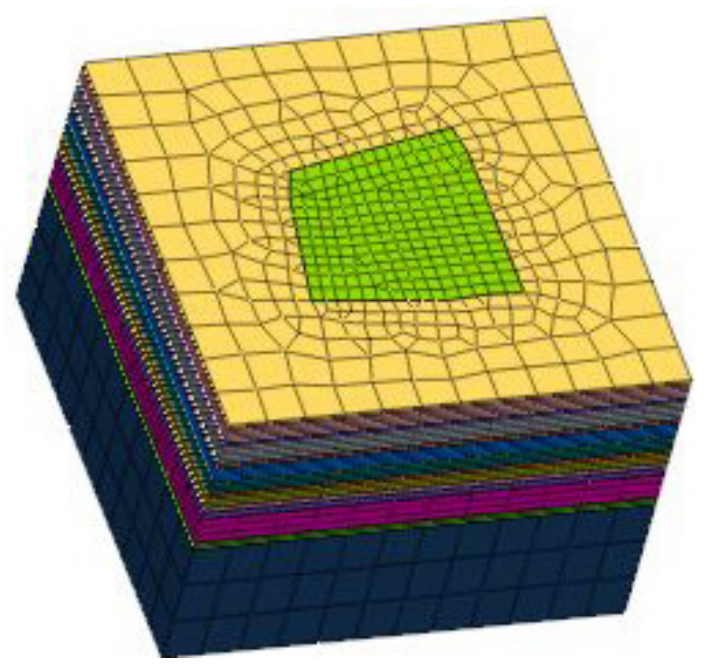

Figure 7. Three-Dimension Model of Foundation Pit Simulation

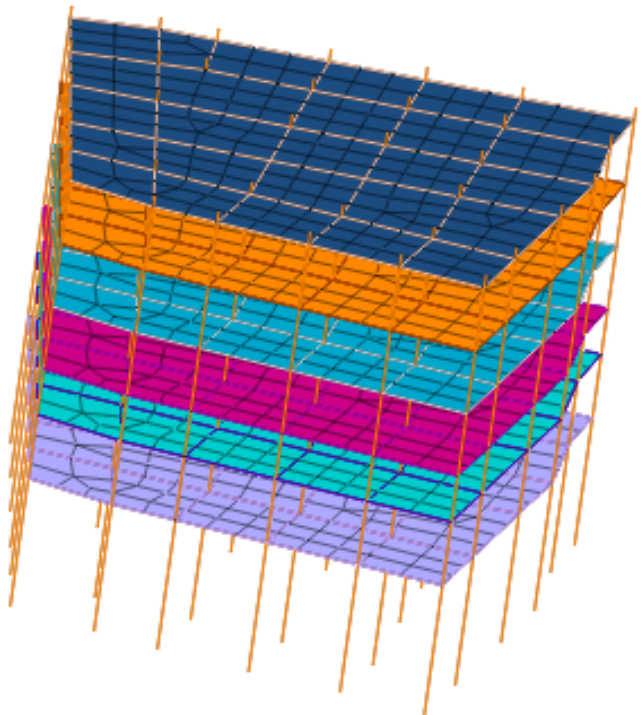

Figure 8. Internal Bracing Supporting Structure

As the size of the mesh will have a certain impact to the speed and accuracy in the process of numerical simulation calculation, The meshing denser, the higher the calculation accuracy and calculation run time will be longer, The meshing sparser, the lower the calculation accuracy and calculation run time will be shorter .Considering all kinds of factors, the rules of meshing are: The internal part of the foundation pit model has a denser mesh generation, the size of each unit is limited in $3 \mathrm{~m}$; the mesh size out the foundation pit is larger but limited in $9 \mathrm{~m}$. The total number of model units is 18,979; the total number of nodes is 17,019. The unit type of the mesh is hexahedron with eight nodes and pentahedron with six nodes; the unit body is obtained by expanding the divided mesh to the excavation direction, the vertical extension distance in the process of expanding is determined by the key points such as vertical soil layer and support construction. The constructive model of the soil is Mohr-Coulomb Model [11]. The diaphragm walls are using slab unit, the horizontal supporting structures and basement pile columns are all using beam unit. The linear elastic material is simulated [12]. Limit the horizontal deformation at the vertical edges of the model; limit the horizontal deformation and the vertical deformation at the bottom surface boundaries of the model [13].

\subsection{Define the Construction Phase}

According to the practical construction process, there are six conditions in this model to simulate the main phases.

The condition 0 is define the initial stage, simulate the stress field under the action of self-weight of the soil, and activate all soil layers mesh first, then activate the foundation boundary and the self-weight of soil, finally activate the pile columns and diaphragm wall.

The condition 1 is: excavate to $-1.0 \mathrm{~m}$, passive the soil and activate the first horizontal beam and slab supporting structure; the condition 2 is: excavate to $-6.4 \mathrm{~m}$, passive the soil and activate the second horizontal beam and slab supporting structure; the condition 3 is: excavate to $-11.7 \mathrm{~m}$, passive the soil and activate the third horizontal beam and slab supporting structure; the condition 4 is: excavate to $-17.0 \mathrm{~m}$, passive the soil and activate the forth horizontal beam and slab supporting structure; the condition 5 is: excavate to $-20.9 \mathrm{~m}$, passive the soil and activate the fifth horizontal beam and slab supporting structure; the condition 6 is: excavate to the bottom of fifth floor, bottom of the longitudinal beam slabs, and longitudinal beams, then passive the soil and activate the bottom beam slab.

\section{Results Analysis and Comparison}

\subsection{Analysis of Simulation Results}

The deformation clouds of diaphragm wall supporting structures is gained by analyzing and calculating the model, extract the simulated data of horizontal displacement of the node in the south which close to the corner, and separate it with appropriate dots, the numerical simulated curve is gained; the curve are given in figure 9.

(1)At the beginning of excavation, the horizontal displacement of diaphragm wall is small, but the displacement is increase with the excavation depth increase, because of the loose soil and small stress of the upper strata, the displacement of wall top in this condition1 is $3.35 \mathrm{~mm}$. The displacement of wall top shows an increasing trend with the continuation of soil excavation, The maximum displacement of the excavation to the bottom of the foundation pit wall is $7.05 \mathrm{~mm}$, less than the maximum alert $20 \mathrm{~mm}$ of deformation, meet the requirements of construction and design specifications.

(2) It is shown by the position of the maximum lateral displacement that occurs in each working condition, The maximum lateral displacement of wall happened in the depth between $\mathrm{Hc}-3 \mathrm{~m}$ to $\mathrm{Hc}+2 \mathrm{~m} \quad(-3$ means $3 \mathrm{~m}$ above the 
excavation surface, +2 means $2 \mathrm{~m}$ below the excavation surface), that is to say it occurs on the foundation pit surface after completion of each condition. The result is accorded with Xu Zhonghua's [14] result that the maximum lateral displacement happens near the excavation surface. The maximum displacement happens at $21.3 \mathrm{~m}$ of the corresponding excavation depth, the accumulated maximum deformation biased towards the internal pit is $16.20 \mathrm{~mm}$.

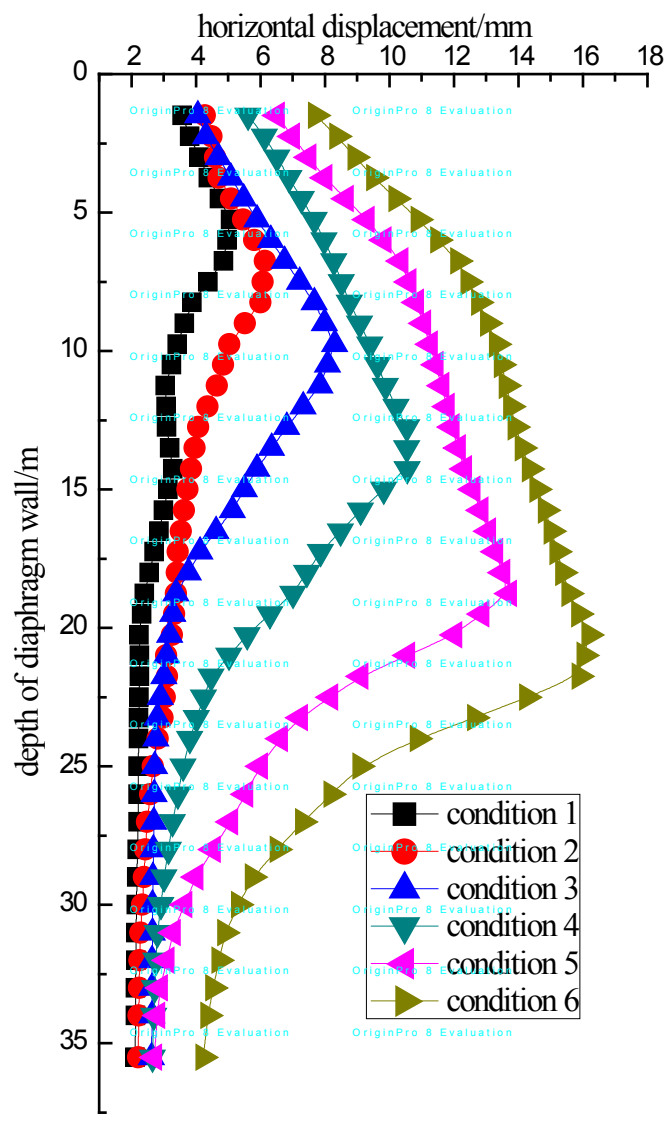

Figure 9. Simulated Horizontal Displacement Curve of Diaphragm Walls

(3) The bottom displacement of diaphragm wall has little changed in the construction process, the final accumulated deformation is $4.16 \mathrm{~mm}$, and the main reason is the embedded depth of the wall is $9 \mathrm{~m}$ deep in the Intermediary Weathered Stratum Shaly Sand, the deformation was limited. The final lateral deformation curve shows a small deformation range at two sides and a large deformation range at the center.

\subsection{Analysis of Measured Results}

In the construction process of foundation pit, the stress state of soil has a great change; The CX-806D inclinometer is used to monitor the deformation to monitor and optimize the construction parameters in the construction process. Draw the data which is gained from TS- 02 measuring point into curves, the curves are given in figure 10.

(1) At the initial stage, the variation range of deformation and absolute amount of deformation are all small, the maximum lateral displacement occurred in $16 \mathrm{~m}$ depth of foundation pit and the deformation is $7.87 \mathrm{~mm}$, the main reason is the excavated soil at initial stage is light weighted unconsolidated miscellaneous fill; the earth pressure stress to the wall is small too. So the unloading effect of the excavated soil has little influence on the deformation of the diaphragm wall, Along with the excavation construction constantly, the excavation depth are 6.4, 11.7, 17,20.9 m wall lateral to the foundation pit displacement were 2.07 , $4.36,7.71,8.88 \mathrm{~mm}$ respectively, and with a rising trends.

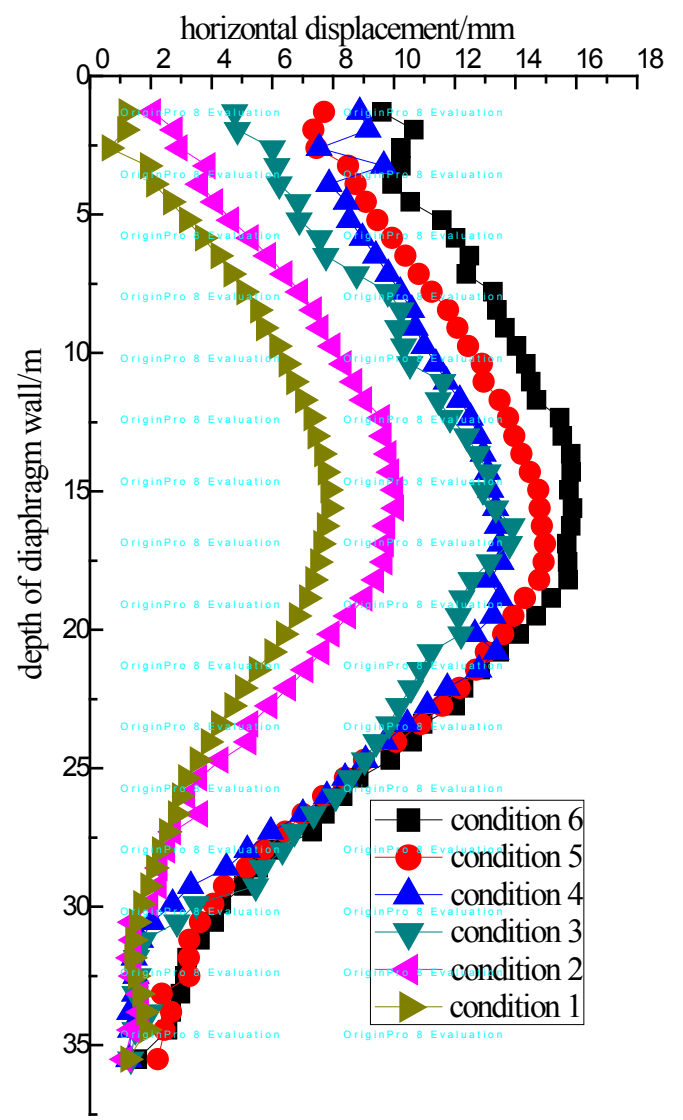

Figure 10. Measured Horizontal Displacement Curve of Diaphragm Walls

(2) The lateral deformation of diaphragm wall increases over time, with the increase of excavation depth and the earth pressure of the basement, the maximum deformation is mostly distributed at the middle depth. The maximum lateral deformation of excavation to the base elevation was 15.88 $\mathrm{mm}$. Wall deformation is weak under the bottom excavation surface in the case of embedding effect, and the final deformation of bottom of diaphragm wall towards interior is $1.56 \mathrm{~mm}$.It is shown that the inlay effect is very obvious and deformation can be limited by increasing the insertion depth of the diaphragm wall below the excavation surface of the basement.

(3) The deformation trend is bow-shaped curve; the lateral deformation of wall top is significantly larger than the deformation of its bottom. The reason is the first layer of internal supporting structure is $1 \mathrm{~m}$ below the wall top excavation surface, it forms a stress type like cantilever, the 
supporting structure does not play an effective role in restriction; so the accumulated deformation is increasing and reached $9.21 \mathrm{~mm}$ at the end, meeting the requirements of design code for construction and alert values.

\subsection{Contrastive Analysis of Measured and Simulated}

(1) By compare figure 9 and figure 10, the conclusion is clear that the simulation results are similar with the monitoring results, but the simulation data is smaller than measured data, because the influential factors are variously, failed to consider the temporary load may come up in the process of construction such as car-driving and material of temporary piled up, the differences are acceptable.

(2) The simulated deformation placement is smaller than the practical situation, because the simulated procedure has a tighter connection surpass reality. In practical situation, due to the objective conditions, concrete pouring is always delayed after excavation so there is no internal supporting to prevent the deformation expanding. But the trend of the overall deformation of the two is basically consistent, which verifies the rationality of the simulation and plays a guiding role in the construction.

(3)In order to reflect the ratio relationship between the maximum lateral displacement value and the excavation depth $\delta_{h m} / H_{e}\left(\delta_{h m}\right.$. maximum lateral displacement, $H_{e}$ :excavation depth) and described the stability of the foundation pit during excavation. The curves are given in figure 11 .

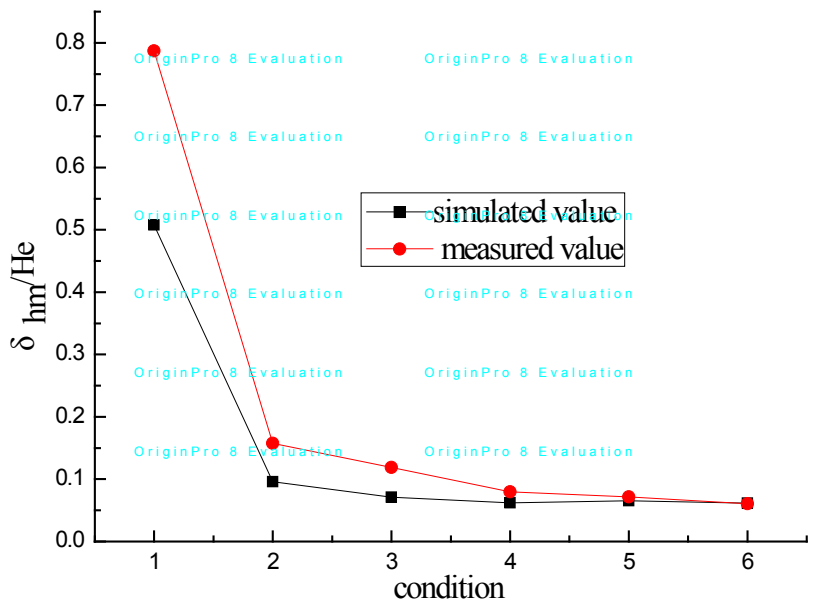

Figure 11. $\delta_{h m} / H_{e}$ Curve of Each Condition

Through the curve can be found in condition 1, simulated value and the measured values $\delta_{h m} / H_{e}$ were $0.508 \%$ and $0.787 \%$, beyond the Zhang Wengang [15] so-thought $0.5 \%$, who thought the $\delta_{h m} / H_{e}$ would maintained within $0.5 \%$ can be effective to keep the stability and safety of the foundation pit and surrounding soil and the building. In the condition 1 , it is needed to strengthen the reinforcement and monitor of the diaphragm wall, ensure the stability of the pit.
With the proceed of the excavation, $\delta_{h m} / H_{e}$ decreased obviously and be inferior to $0.5 \%$ which indicated that the foundation pit grew stability step by step and meet the relevant safety standards.

(4)It is showed that the maximum deformation position appears near the excavation surface obtained by simulation and actual measurement .Therefore, in the actual construction process at this stage need to strengthen the monitoring of displacement and deformation, Reducing the time of exposure of the excavation surface, pouring beam-slab concrete and strength formation as soon as possible which is very effective for deformation control.

\section{Conclusions}

This paper analyzed the foundation pit engineering of Hefei New Traffic Building by using MIDAS/GTS finite element software to do numerical simulation on the lateral displacement of diaphragm wall and compared with the monitoring data, studied the conclusions are drawn as follows:

(1) The calculation results of the finite element model and measured data showed that: the deformation of the early excavation had an obviously influence to the whole construction. In condition 1 , the simulated and the measured of the deformation were $5.08 \mathrm{~mm}$ and $7.87 \mathrm{~mm}$ respectively, which contained $31.37 \%$ and $49.56 \%$ of the final maximum deformation. Therefore, strengthen the control of the initial stage of the deformation to foundation pit final deformation have better limit function

(2) With the continuous of digging, the lateral displacements of diaphragm wall are increase, and the place of maximum displacement went down, and all appears near the excavation surface, and the depth is between Hc-3 and $\mathrm{Hc}+2 \mathrm{~m}$. The foundation pit stability comes with the completion of excavation, and the deformation trend is a bow-shaped curve. Finite element simulation of deformation of foundation pit construction process trends is basically identical with the measured data.

(3) Through the deformation and displacement analysis of each working condition. The displacement of the wall bottom is small; its displacement is $4.16 \mathrm{~mm}$ at the final excavation depth, which shows that a higher insertion ratio is effective to the limitation of lateral displacement and maximum displacement.

(4) Under the construction condition of Reverse Method, the diaphragm wall and beam-floor bracing system could limit the foundation deformation effectively. The internal support is the support form of the deep foundation pit, which not only can reasonably select the supporting material and the arrangement of the supporting system according to the local conditions, but also fully coordinate and exert the mechanical properties of the various components. Besides, it has other advantages such as safety, reliability, low-price, short construction period, convenient, and environmentally-friendly. 


\section{Acknowledgements}

This project supported by Anhui Provincial Science and Technology Research Project Funding through grant No.1501041133, and Anhui Provincial Universities Natural Science Research Project No. KJ2015A046.

\section{REFERENCES}

[1] SUN. Chang-jun, ZHANG. Ding-li, LIU. Jing-xue, CAO. Xiao-li. Mechanical and Deformation Characteristics of Diaphragm Wall System of Beijing Metro Station, Chinese Journal of Geotechnical Engineering, S1: 78-83, 2015.

[2] QIU. Jian-chun, SHI. Ai-xiang, XIA You-chao, YIN Jian-feng, CAI Ting-ting. 3-D Finite Element Analysis on Spatial Deformation of Double- row Cellular Continuous Diaphragm Wall, Technology of Water Conservancy and Hydropower, 08: 78-82, 2014.

[3] XIONG. Xiao-bo, GUI. Guo-qing, ZHENG. Ming-xin, XU. Jian-cong. Numerical Simulation of Bracing Structure Deformation For a Deep Pit Foundation Based on ANSYS Software, Chinese Journal of Underground Space and Engineering, S1: 1298-1305, 2009.

[4] DU. Xi-lei. Displacement Analysis on Prop-structure For Diaphragm Wall of Deep Foundation Pit, Yangzhou University, 2011.

[5] DING. Ke-sheng, ZHANG. Yi-jia. Relationship between Lateral Deformation of Diaphragm Wall of Deep Foundation Pits and Earth Pressure in Tianjin, Chinese Journal of Geotechnical Engineering, S1: 9-11, 2008.

[6] REN. Jian-xi, ZHANG. Yin-he, ZHANG. Kun, GAO Bing, li. Research on the Deformation Law of Deep Foundation Pit of Metro Station in $\mathrm{Xi}$, and by FLAC Simulation, Journal of Railway Engineering Society,03:90-93,2011.
[7] QIAO. Rui-long. The Deformation Laws Research of Supporting Structure of Deep Foundation Pit During Excavations, $\mathrm{Xi}$, an: Xi'an University of Architecture and Technology, 2011.

[8] Long M. Database for Retaining Wall and Ground Movements due to Deep Excavations, Journal of Geotechnical and Geo-environmental Engineering, ASCE, 127(33):203-22,2001

[9] Finno R J and Bryson L S. Response of Building Adjacent to Stiff Excavation Support System in Soft Clay, Journal of Performance of Constructed Facilities, ASCE,16(1): $10-20,2002$

[10] ZOU. Xiao-qin. Numerical Simulation on Foundation Pit Excavation of Subway Station, Huazhong University of Science \& Technology, 2009.

[11] ZHAO. Yuan- yuan, ZUO. Ren. yu, LU. Zhao, ZHAI Dong-ge. Contrast Application on Constitutive Model in Excavation Numerical Analysis, Low Temperature Architecture Technology, 08: 102-105, 2015.

[12] SHEN. Lei, LU. Yu-nian, YUE. Jian-yong. Deformation Characteristics of Oversized Deep Foundation Pit: Comparison of Numerical Simulation with the Instrumentation Results, Chinese Journal of Underground Space and Engineering, 04: 538-542, 2005.

[13] YANG. Wen-guan. Monitoring and Numerical Simulation Analysis for Deep Foundation Pit in Soft Soil Foundation, Central South University, 2014.

[14] XU. Zhong-hua. Deformation Behavior of Deep Excavations Supported by Permanent Structure in Shanghai Soft Deposit, Shanghai Jiao Tong University, 2007.

[15] Zhang, W., Goh, A., and Zhang, Y. Probabilistic Assessment of Serviceability Limit State of Diaphragm Walls for Braced Excavation in Clays, ASCE-ASME J. Risk Uncertainty Eng. Syst., Part A: Civ. Eng., 10.1061/AJRUA6.0000827, $06015001,2015$. 